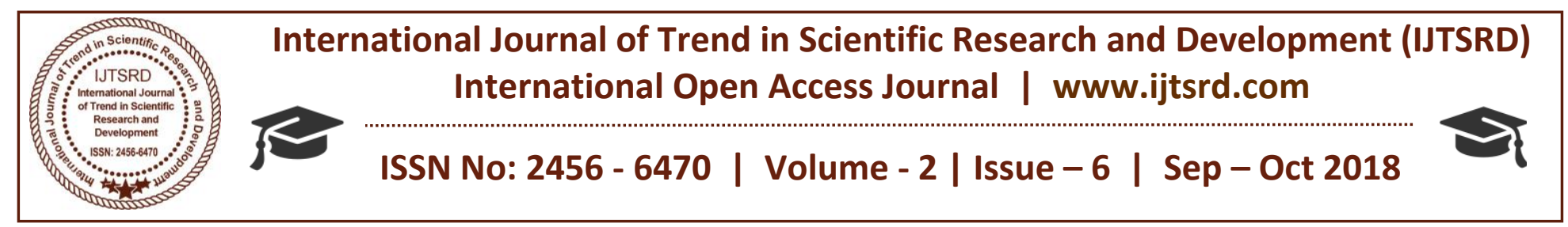

\title{
Measurement of pH of the Three Nano Fluid and Development of New Correlations
}

\author{
M. Raniammal \\ Lecturer (Senior Grade)/Chemistry \\ Ayya Nadar Janaki Ammal Polytechnic College, Sivakasi, Tamil Nadu, India
}

\section{ABSTRACT}

In this study the $\mathrm{pH}$ levels of aluminium oxide (A12O3), silicon dioxide (SiO2), and zinc oxide $(\mathrm{ZnO})$ nanoparticles dispersed in propylene glycol and water mixture were measured in the temperature range of $00 \mathrm{C}$ to $90 \circ \mathrm{C}$. The volumetric concentration of nanoparticles in these fluids ranged from 0 to $10 \%$ for different Nano fluids. The average particle sizes (APS) considered was from $10 \mathrm{~nm}$ to $70 \mathrm{~nm}$. The $\mathrm{pH}$ measuring apparatus and the measurement procedure were validated by measuring the $\mathrm{pH}$ of a calibration fluid, whose properties are known accurately. The measured $\mathrm{pH}$ values agreed within less than $\pm 0.5 \%$ with the published data reported by the manufacturer. Following the validation, the $\mathrm{pH}$ values of different Nano fluids were measured. The measurements showed that $\mathrm{pH}$ of Nano fluids decreased with an increase in temperature and increased with an increase in particle volumetric concentration. For the same Nano fluid at a fixed volumetric concentration, the $\mathrm{pH}$ was found to be higher for larger particle sizes. From the experimental data, empirical models were developed for three Nano fluids to express the $\mathrm{pH}$ as functions of temperature, volumetric concentration, and the size of the nanoparticles.

Keyword: Nano fluids, average particle sizes (APS), $\mathrm{SiO}$, Al2O3, $\mathrm{ZnO}$

\section{INTRODUCTION}

In the handbook by Nalwa [1] it is described in detail how the adhesive force and friction present in aqueous Nano fluids depend on their $\mathrm{pH}$ values. Depending on the degree of ionization, electrostatic forces arise between the charged nanoparticles suspended in the fluids. Therefore, the $\mathrm{pH}$ of a Nano fluid must be known to assess its influence on fluid friction that is related to the viscosity and rheological behaviour of Nano fluids. Nalwa also presents experimental data showing that the contact angles of Nano fluids depend on its $\mathrm{pH}$, again stressing the idea that an accurate knowledge of the $\mathrm{pH}$ of Nano fluids is very important.

Li et al. [2] through experiments on copper-water Nano fluid showed that the thermal conductivity of the Nano fluids varied widely with the variation of their $\mathrm{pH}$. The thermal conductivity of this Nano fluid increased as the $\mathrm{pH}$ increased from a value of 2 , reaching a peak around $\mathrm{pH} 9$, and then decreased until a $\mathrm{pH}$ value of 12 was reached. Therefore, there is an optimum value of $\mathrm{pH}$ that ensures the highest thermal conductivity. They also showed that the zeta potential of a 0.05 weight percentage $\mathrm{Cu}-\mathrm{H} 2 \mathrm{O}$ Nano fluid steadily diminished from $\mathrm{pH} 2$, reaching the lowest values at $\mathrm{pH}$ around 9 and then gradually increasing up to a $\mathrm{pH}$ of 12 . Since zeta potential dictates the repulsive electrostatic force between charged particles, this shows that the knowledge of $\mathrm{pH}$ is necessary to evaluate the dispersion stability of Nano fluids.

Li et al. [3] studied the dispersion behaviour of the aqueous copper Nano fluid. Their experiments showed that at $\mathrm{pH} 9.5$ the zeta potential of the suspension is higher, therefore generating strong repulsive forces to provide the best stability of the copper powder suspension. They also found that at a $\mathrm{pH}$ below 2, the zeta potential of the particle surface is at a minimum, so the force of electrostatic repulsion is not sufficient to overcome the force of attraction between particles. Thus, at lower $\mathrm{pH}$ values the dispersion stability is poor due to particle coagulation leading to settling and sedimentation.

Wang et al. [4] studied $\mathrm{CuO}$ and $\mathrm{Al} 2 \mathrm{O} 3$ powder with water based Nano fluids of different particle sizes using sodium dodecyl benzene sulfonate (SDBS) as 
the dispersant. Their studies showed that the $\mathrm{pH}$ of Nano fluid was influenced by particle sizes for a fixed concentration. They determined that at an optimal $\mathrm{pH}$ of Nano fluids the best stability behaviour was attained and at that state the thermal conductivity of the Nano fluids exhibited the highest magnitude. Since the convective heat transfer coefficient of a Nano fluid is directly proportional to its thermal conductivity, through Nusselt number, an optimization of conductivity at a given $\mathrm{pH}$ would be attractive to promote higher heat transfer.

Zhu et al. [5] studied the dispersion behaviour and thermal conductivity of $\mathrm{A} 12 \mathrm{O} 3-\mathrm{H} 2 \mathrm{O}$ Nano fluids. Their experiments were conducted within the $\mathrm{pH}$ range of 2 to 12. They also confirmed that the dispersion stability and the thermal conductivity of this Nano fluid were highly dependent on the $\mathrm{pH}$ value of the Nano fluid. They achieved different $\mathrm{pH}$ values of Nano fluids by the addition of different proportions of $\mathrm{HCl}$ and $\mathrm{NaOH}$ solutions. At a $\mathrm{pH}$ value around 8 , the absolute value of zeta potential was the highest, causing the electrostatic repulsion force between particles to become the strongest. Therefore, this $\mathrm{pH}$ value thas recommended by them to attain the maximum thermal conductivity enhancement for this Nano fluid.

Lee et al. [6] dispersed $25 \mathrm{~nm}$ mean diameter copper oxide nanoparticles in deionized water. They did not use any surfactant or dispersant in the preparation of their Nano fluids. Their particle size measurements showed a size range of agglomerated particles from 160 to $280 \mathrm{~nm}$ within a $\mathrm{pH}$ range of 3 to 11 . Their thermal conductivity measurements showed a maximum enhancement of $12 \%$ over that of the base fluid at the lower $\mathrm{pH}$ of 3 , while at a $\mathrm{pH}$ of 8 , the enhancement was negligible. However, at a $\mathrm{pH}$ of 11 the thermal conductivity value again increased by about $11 \%$. They concluded that the surface charge states of nanoparticles were a basic parameter that enhanced the thermal conductivity of Nano fluids.

Wamkam et al. [7] studied two Nano fluids made from zirconium dioxide ( $\mathrm{ZrO} 2)$ and titanium dioxide (TiO2) particles at $3 \%$ by weight, dispersed in deionized water. They showed that the $\mathrm{pH}$ affected the zeta potential, particle size distribution, viscosity, and thermal conductivity of Nano fluids. Slightly higher than $20 \%$ enhancement of thermal conductivity was reported near the isoelectric point, which occurred near $\mathrm{pH} 6.1$ for the $\mathrm{ZrO} 2$ Nano fluid and near $\mathrm{pH} 4$ for the TiO2 Nano fluid in their experiments.
Younes et al. [8] conducted experiments on $\mathrm{Fe} 2 \mathrm{O} 3$ $(20-60 \mathrm{~nm})$ and $\mathrm{CuO}(30-50 \mathrm{~nm})$ powder dispersed in three different base fluids: (a) water, (b) ethylene glycol, and (c) water with sodium dodecyl benzene sulfonate surfactant. They presented results of zeta potential and average particle sizes measured at different $\mathrm{pH}$ values ranging from 3 to 12 . They measured thermal conductivity of Nano fluids of $0.4 \%$ volumetric concentration at room temperature. They also studied the influence of magnetic field on enhancing the thermal conductivity of Nano fluids containing magnetic particles of $\mathrm{Fe} 2 \mathrm{O} 3$. Their results showed that the thermal conductivity value of Fe2O3water Nano fluid increased from $0.73 \mathrm{~W} / \mathrm{m}-\mathrm{K}$ to 1.12 $\mathrm{W} / \mathrm{m}-\mathrm{K}$ under a magnetic field of $0.12 \mathrm{Kg}$ due to the alignment of nanoparticles. They presented that the addition of the surfactant reduced the $\mathrm{pH}$ value of $\mathrm{Fe} 2 \mathrm{O} 3$ in water from 4.88 to 3.97 . However, the $\mathrm{CuO}$ nanofluid exhibited minor reduction in $\mathrm{pH}$ from 9.46 to 9.23 due to the addition of surfactant.

Huang et al. [9] studied Al2O3 (15-50 nm) and copper (25-60 nm) nanoparticles dispersed in water. They used SDBS dispersant at $0.1 \mathrm{wt} \%$ for preparing their Nano fluids. The particle concentration in Nano fluids they studied was also $0.1 \mathrm{wt} \%$. They measured the zeta potential and absorbency of these Nano fluids. For $\mathrm{Al} 2 \mathrm{O} 3$ Nano fluid, the $\mathrm{pH}$ in the range of 7.5-8.9 showed the highest absolute value of zeta potential and good dispersion of nanoparticles.

Timofeeva et al. [10] studied the Al2O3 nanoparticles in 50:50ethylene glycol and water (EG/W). They showed that the viscosity of this Nano fluid can be decreased by $31 \%$ without affecting its thermal conductivity, by adjusting the $\mathrm{pH}$ of this suspension.

Extensive research on Nano fluids during the past decade has proven that the convective heat transfer capability of Nano fluids is significantly higher than that of their base fluids. Kulkarni et al. [11] conducted experiments in a circular tube and measured an enhancement of the convective heat transfer coefficient by $18 \%$ at a Reynolds number of 8800 for a $10 \%$ volumetric concentration of $\mathrm{SiO} 2$ nanoparticles dispersed in ethylene glycoland water mixture. Since this promise is evident, the $\mathrm{pH}$ values of the Nano fluids that ensure highest thermal conductivity and highest convective heat transfer must be accurately known.

All the research just summarized points to the fact that the $\mathrm{pH}$ values of different Nano fluids play an important role. Yet only a limited amount of data has 
appeared in the literature on the $\mathrm{pH}$ value of Nano fluids. To the best of our knowledge, no theoretical or empirical relation for $\mathrm{pH}$ has been presented for Nano fluids thus far. Therefore, it was the objective of this study to measure the $\mathrm{pH}$ of various Nano fluids and develop empirical correlations to express them. From the experimental evidence available on the thermo physical properties of Nano fluids, for example, viscosity, thermal conductivity, specific heat, and so on, it is surmised that the $\mathrm{pH}$ should be a function of the base fluid physical property, temperature, particle size, and particle volumetric concentration. Therefore, three types of nanoparticles-aluminiumoxide (Al2O3), zinc oxide ( $\mathrm{ZnO})$, and silicon dioxide (SiO2), two metallic and one non-metallic-were chosen for this study. A mixture of propylene glycol and water, PG/W 60:40 by mass, was selected as the base fluid for our study. The reason for selecting this base fluid is its wide use in cold climatic conditions. The 60:40 mixture of PG/W guarantees an extremely low freezing temperature of $-51^{\circ} \mathrm{C}$. In colder regions of the world significant benefit can be derived from Nano fluids by using them in building heating and as automobile coolant. For example, in Alaska nearly $40 \%$ of energy consumption goes to heating the buildings. For freeze protection, glycol-water solution is widely used as building and automobile heat transfer fluids in cold climates. Therefore, propylene glycol-water-based Nano fluids were selected in our study, which would have a large-scale application in regions where water as a heat transfer fluid would freeze during the long winter season. The PG/W mixture is nontoxic, whereas the EG/W mixture is toxic. Therefore, it is prohibited in applications where potable water lines and glycol lines are interconnected.

It is understood that different Nano fluids obtained from different manufacturers may contain their own special surfactant or dispersant for the stable suspension of nanoparticles. These additives may vary among other manufacturers, which will affect the $\mathrm{pH}$ values. Therefore, the empirical correlations developed here for the $\mathrm{pH}$ of three different Nano fluids obtained from different manufacturers are not universal. However, this study has identified the dependence of the $\mathrm{pH}$ of Nano fluids on three major parameters, namely, temperature, concentration, and particle sizes. The correlation presented in this paper linking those parameters can serve as a first approximation to estimate the $\mathrm{pH}$ values of Nano fluids.

\section{EXPERIMENTAL SETUP AND PROCEDURE \\ Material Preparation}

In this study three types of nanofluids, namely, $\mathrm{Al} 2 \mathrm{O} 3, \mathrm{SiO} 2$, and $\mathrm{ZnO}$ nanoparticles dispersed in PG/W, were used. Pure laboratory-grade propylene glycol was mixed with deionized water in a proportion of 60 to 40 by mass using an electronic mass balance apparatus. Original concentrated aqueous suspensions of the aforementioned nanofluids were procured from Alfa Aesar [12] and Nanostructured and Amorphous Materials, Inc. [13]. These manufacturers have already developed successful surfactant or dispersant for several types of nanofluids. All of the three nanofluids purchased were stable suspensions, and settling was not observed in these nanofluid bottles, until they had sat on our laboratory shelves for several weeks. Furthermore, whatever partial sedimentation occurred to concentrated parent nanofluids after remaining stagnant for months was easily well dispersed by subjecting the nanofluid bottles to several hours of sonication in a bath-type sonicator. The characteristics of materials procured for our experiments are tabulated in Table 1.

Table 1: Material characterization of parent Nanofluids used in parent experiment

\begin{tabular}{|l|c|c|c|}
\hline \multicolumn{1}{|c|}{ Manufacturer } & Material & $\begin{array}{c}\text { Average particle } \\
\text { size, } \mathrm{nm}\end{array}$ & $\begin{array}{c}\text { Parent Nanofluid } \\
\text { concentration, wt\% in } \mathrm{H}_{2} \mathrm{O}\end{array}$ \\
\hline Alfa Aesar[12] & $\mathrm{Al}_{2} \mathrm{O}_{3}{ }^{*}$ & 20 & 30 \\
\hline Alfa Aesar & $\mathrm{Al}_{2} \mathrm{O}_{3}{ }^{*}$ & 45 & 20 \\
\hline $\begin{array}{l}\text { Nanostructured and Amorphous } \\
\text { Materials, Inc.[13] }\end{array}$ & $\gamma-\mathrm{Al}_{2} \mathrm{O}_{3}$ & 10 & 25 \\
\hline $\begin{array}{l}\text { Nanostructured and Amorphous } \\
\text { Materials, Inc. }\end{array}$ & $\mathrm{SiO}_{2 \mathrm{z}}$ & 30 & 40 \\
\hline Alfa Aesar & $\mathrm{ZnO}$ & 36 & 50 \\
\hline Alfa Aesar & $\mathrm{ZnO}$ & 70 & 25 \\
\hline
\end{tabular}

\section{Sonication}


The sonications of nanofluids were carried out in two stages. First, the bottle containing aqueous concentrated parent nanofluid as supplied by the vendor was sonicated. The bottle was subjected to ultra-sonication in a Branson model 5510 sonicator [14] under a frequency of $40 \mathrm{kHz}$ and a power of 185 W. The ultra-sonicator bath was filled with water up to the designated operating level. Then the water was degassed for 5 min for removal of dissolved gases as instructed by the manufacturer. The parent nanofluid was contained in a glass bottle, with a gasket, screwed cap to prevent escape of water vapour, so that the concentration could not change. Then the bottle was placed in the sonicator water bath and the nanofluid was sonicated anywhere from 4 to $9 \mathrm{~h}$, depending on the degree of sedimentation, until the liquid volume showed a uniform dispersion of nanoparticles under careful visual observation.

\section{Sample Preparation}

From these concentrated parent nanofluids, test samples of different volumetric concentration were prepared. The exact mass of PG/W (60:40) mixture was calculated to attain a desired volumetric concentration of nanofluid. Next, using a precise electronic mass balance, the calculated amount of PG/W (60:40) mixture was added to the concentrated nanofluid by pipettes to reach the exact level of particle volumetric concentration. In this way nanofluid samples starting with $1 \%$ volumetric concentration to a maximum of $10 \%$ were prepared. It was only the high concentration of $45 \mathrm{~nm} \mathrm{Al} 2 \mathrm{O} 3$ parent fluid with the initial concentration of $50 \%$ that yielded a $10 \%$ concentration sample. The other parent nanofluids yielded maximum sample concentrations of $\leq 5 \%$. Each nanofluid sample of different volumetric concentration was sonicated for 1 to $2 \mathrm{~h}$ additionally just prior to the measurement of their $\mathrm{pH}$ values.

\section{Particle Size Measurement}

In order to ensure that no agglomerated particles are presentin the sample prior to the $\mathrm{pH}$ measurement, each type of nanofluid sample was examined for particle size distribution under a transmission electron microscope (TEM). Figure 1 shows the TEM image of one of the $\mathrm{Al} 2 \mathrm{O} 3$ nanofluid samples. The TEM image showed that there were no agglomerated particles. The TEM result for this nanofluid is consistent with the data providedby the vendor. This sample was Alfa Aesar's Al2O3 nanofluid with its specification average particle size $($ APS $)=20 \mathrm{~nm}$. We notice from the TEM image that a majority of nanoparticles fall near this average size, with a few smaller and a few larger ones, which should yield an overall average particle size of $20 \mathrm{~nm}$. From similar TEM images of the other two nanofluids, containing $\mathrm{ZnO}$ and $\mathrm{SiO} 2$ nanoparticles, no agglomeration was observed. This is due to two effects: (a) the nanofluid manufacturers have developed successful surfactant or dispersant that is already present in these purchased nanofluids, making them stably suspended and free from agglomeration or coagulation. (b) Second, the sonication of the parent concentrated nanofluids before sample preparation followed by the second sonication of the dilute sample prior to the $\mathrm{pH}$ measurements ensures breaking up of agglomerated particles, if any.

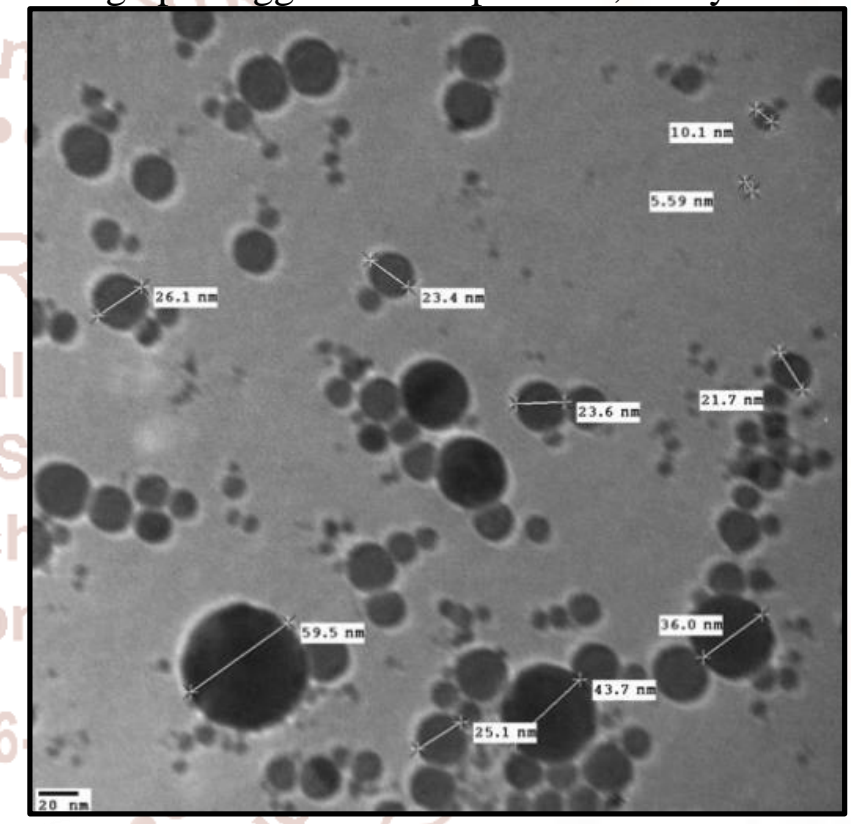

Figure 1: TEM image of $\mathrm{Al}_{2} \mathrm{O}_{3}$ nanoparticles taken before the measurement of $\mathrm{pH}$

\section{Experimental Setup}

The experimental setup for measuring the $\mathrm{pH}$ of nanofluids, shown in Figure 2, consists of a Hanna HI $4521 \mathrm{pH}$ bench meter [15]. The $\mathrm{pH}$ probe HI 1131 and the temperature probe HI7662-T were immersed to a depth of $4 \mathrm{~cm}$ into the nanofluid for correct reading. While immersed in the nanofluid column, the $\mathrm{pH}$ probe measures the value of $\mathrm{pH}$ and the temperature probe measures the temperature of nanofluid $\left({ }^{\circ} \mathrm{C}\right)$. For measurements above room temperature the nanofluids were heated by an approximate increment of $10^{\circ} \mathrm{C}$ to various temperature levels up to $90^{\circ} \mathrm{C}$ by a VWR model 320 heater [16]. The time for each $10^{\circ} \mathrm{C}$ rise of the sample was about 3 to $5 \mathrm{~min}$. The beaker containing the nanofluid was covered with a silicone pad, as shown in Figure 2, to 
minimize any vapour escaping from the container. The times of heating were small and the silicone pad prevented any appreciable change in the concentration of nanofluids. The heater has the capability to stir the liquid with a magnetic stirrer at different rpm to help disperse the nanoparticles uniformly. The stirrer was removed from the beaker when $\mathrm{pH}$ was being measured to eliminate its effect on readings. The accuracy of the $\mathrm{pH}$ meter specified by the manufacturer is $\pm 0.002 \%$ of the reading. According to the specification of the manufacturer, this $\mathrm{pH}$ meter and the probe have the capability to measure $\mathrm{pH}$ values from -2.000 to 20.000 with settings in four ranges for four different resolutions. Although the early conception was that the $\mathrm{pH}$ scale lay between 0 and 14 , research in past decades has extended this range of $\mathrm{pH}$. Nordstorm et al. [17] have found the $\mathrm{pH}$ of extremely acidic mine waters at as low as -3.6. Lim [18] reports commercially available saturated $\mathrm{NaOH}$ solution with $\mathrm{pH}$ 15. The instrument manufacturers have kept pace with the advancement by designing the meter to measure $\mathrm{pH}$ beyond 0 and 14. The liquid temperature range over which the meter and probes are effective is -20 to $120^{\circ} \mathrm{C}$, although we only made measurements down to $0^{\circ} \mathrm{C}$. For measurements at temperatures lower than room temperature, the nanofluid samples were cooled in a temperature-controlled freezer (FS 202 Chamber) [19]. Due to the additional time required in the freezer chamber at low temperature, each sample was ultrasonicated for $3 \mathrm{~h}$ before being placed in the freezer chamber. A steady-state temperature down to $0^{\circ} \mathrm{C}$ was reached within about $30 \mathrm{~min}$, after which the sample was placed on the test bench for $\mathrm{pH}$ measurements.

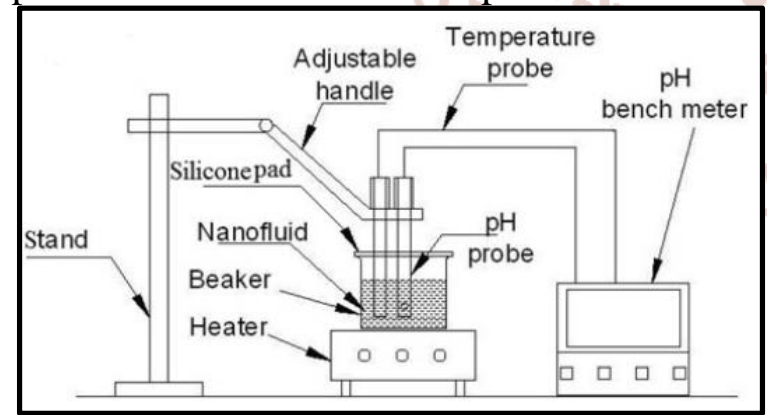

Figure 2: Experimental setup for measuring the $\mathrm{pH}$ of nanofluid

\section{Benchmark Test Case}

The benchmark tests of the $\mathrm{pH}$ meter and the probes were performed using the $\mathrm{pH}$ calibration liquid of Hanna, designated as HI 7001. The manufacturer recommends testing the equipment with this buffer solution to ensure that the meter, probes, and measurement procedures are correct. Following their procedure, we measured $\mathrm{pH}$ values of the calibration liquid at various temperatures, and have plotted the results in Figure 3. For comparison, the $\mathrm{pH}$ values of this calibration liquid provided by the manufacturer have also been plotted in this figure. It was observed that the measured values of the $\mathrm{pH}$ and the values published by the manufacturer differed by less than $\pm 0.5 \%$. The highest deviation between the measured and manufacturer's data was observed at the data point at $283.2 \mathrm{~K}\left(10.2^{\circ} \mathrm{C}\right)$, where it was $-0.356 \%$. Thus, the benchmark test showed that the apparatus was working correctly and that the measurement procedure was correct. With this confirmation, the $\mathrm{pH}$ values of three nanofluids of varying concentrations and particle sizes at temperatures ranging from $273 \mathrm{~K}$ to $363 \mathrm{~K}\left(0-90^{\circ} \mathrm{C}\right)$ were measured. Each $\mathrm{pH}$ measurement was repeated at least twice to check repeatability. The differences between the repeated measurements were less than $\pm 0.5 \%$. The mean values of repeated measurements were recorded as the experimental data.

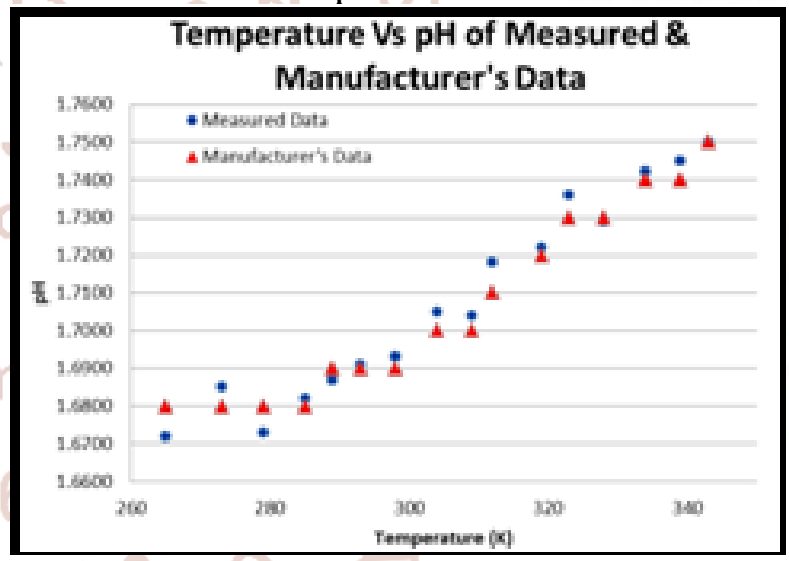

Figure 3: Benchmark test case for the $\mathrm{pH}$ of the calibration solution, HannaHI 7001.

\section{RESULTS AND DISCUSSIONS Base Fluid Data}

In the present study, PG/W (60:40) was used as the base fluid to prepare different types of nanofluids. Therefore, the $\mathrm{pH}$ of this base fluid was measured first, which represented the $\mathrm{pH}$ values when the nanoparticle concentration is zero. The results of this measurement are shown in Figure 4. A second-order polynomial relation fits the data well:

$$
\begin{gathered}
p H_{b f}=0.00015074 T^{2}-0.11270782 T+ \\
26.73630875 \text { with } R^{2}=0.9901
\end{gathered}
$$

Digits up to eight places after the decimal point were retained in each term of the preceding equation, because truncating them did not maintain the accuracy of the equation. Equation (1) is valid in the range 273 $\mathrm{K} \leq \mathrm{T} \leq 363 \mathrm{~K}$. 
This equation can be non-dimensional zed by the $\mathrm{pH}$ of the base fluid $\left(p H_{b f 0}\right)$ at a reference temperature $T_{0}$, which was adopted to be $273 \mathrm{~K}\left(0^{\circ} \mathrm{C}\right)$.

$$
\begin{gathered}
\frac{p H_{b f}}{p H_{b f 0}}=1.56000609\left(\frac{T}{T_{0}}\right)^{2}-4.272570001\left(\frac{T}{T_{0}}\right)^{2}+ \\
3.71256391 \text { with } R^{2}=0.9901
\end{gathered}
$$

Equation (2) is valid in the range $273 \mathrm{~K} \leq \mathrm{T} \leq 363 \mathrm{~K}$. The range of $\mathrm{pH}$ of the base fluid shows that it is slightly in the acidic range.

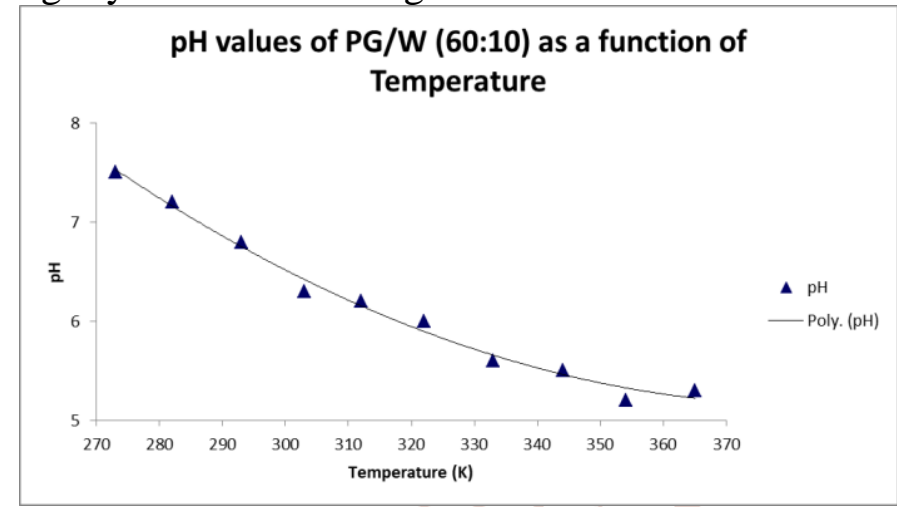

Figure 4: The $\mathrm{pH}$ values of PG/W (60:40) as a function of temperature.

\section{Aluminium OxideNanofluid}

Figure 5 presents a comparison of the $\mathrm{pH}$ of the A12O3 nanofluid in PG/W (60:40) for three average particle sizes, namely, 10, 20, and $45 \mathrm{~nm}$. The 10-nm particles belong to the gamma crystal phase, whereas the 20 - and $45-\mathrm{nm}$ particles belong to $70 \%$ delta and $30 \%$ gamma crystal phases, as presented in Table 1. Several distinct characteristics of nanofluids are observed from this plot. Similar to the $\mathrm{pH}$ variation exhibited by common liquids, the $\mathrm{pH}$ of $\mathrm{Al} 2 \mathrm{O} 3$ nanofluids decreases as the temperature increases. This decreasing trend follows a second-order polynomial dependence on the temperature. As an example, for the 20-nm nanofluid of $3 \%$ concentration, the second-order polynomial variation of $\mathrm{pH}$ with the temperature is given by Eq. (3):

$$
\begin{gathered}
p H_{b f}=-0.00006807 T^{2}+0.02718359 T+ \\
1.47354285 \text { with } R^{2}=0.9927
\end{gathered}
$$

Equation (3) is valid in the range $273 \mathrm{~K} \leq \mathrm{T} \leq 363 \mathrm{~K}$. From the experimental data in Figure 5, it was observed that the addition of $\mathrm{Al} 2 \mathrm{O} 3$ nanoparticles imparts acidic character to the nanofluids. The $\mathrm{pH}$ of $1 \%$ Al2O3 nanofluid of particle sizes 10,20 , and 45 $\mathrm{nm}$ decreased by $27 \%, 37 \%$, and $33 \%$, respectively, when the temperature increased from $273 \mathrm{~K}$ to $363 \mathrm{~K}$ (34\%). A general trend exhibited by the 45-nm particle is that, at a specific temperature, as the volumetric concentration of nanofluid increases, its $\mathrm{pH}$ increases with the exception of a few data points. For example, at a temperature of $323 \mathrm{~K}\left(50^{\circ} \mathrm{C}\right)$, the $\mathrm{pH}$ of the $\mathrm{Al} 2 \mathrm{O} 3$ nanofluid with an average particle size of $45 \mathrm{~nm}$ increases by $21 \%$ when the volumetric concentration increases from $1 \%$ to $4 \%$. At the same temperature of $323 \mathrm{~K}\left(50^{\circ} \mathrm{C}\right)$, the $\mathrm{pH}$ of this nanofluid with $20-\mathrm{nm}$ particle size increases by $4 \%$, when the volumetric concentration increases over the same range from 1 to $4 \%$. This small increase is based on calculations from the measured data and is not easily distinguishable in Figure 5. For the 10-nm particles belonging to a different crystal phase, only 1 and $2 \%$ concentrations were available and their $\mathrm{pH}$ data practically overlap in Figure 5. Therefore, for smaller particle sizes (10 and $20 \mathrm{~nm}$ ), the increase in $\mathrm{pH}$ due to an increase in concentration may be very small in comparison to a larger particle size, at a given temperature. For about $34 \%$ increase in temperature, the $\left(p H_{n f}\right)$ decreases by 27 to $37 \%$, but for an increase in $\varphi$ (volumetric concentration of nanoparticles) from $1 \%$ to $4 \%,\left(p H_{n f}\right)$ increases by 4 to $21 \%$ depending on the size of the particle. Therefore, the variation of $\mathrm{pH}$ of nanofluid shows a stronger dependence on temperature than the volumetric concentration within the ranges of our experiments. It is observed that for the same particle volumetric concentration, at a fixed temperature, nanofluids containing larger nanoparticles (e.g., 45 $\mathrm{nm}$ ) exhibit higher $\mathrm{pH}$ than those containing smaller nanoparticles (e.g., $20 \mathrm{~nm}$ ). Between smaller particle sizes of $10 \mathrm{~nm}$ and $20 \mathrm{~nm}$ the difference in $\mathrm{pH}$ values is not clearly distinguishable in Figure 5.These two nanofluids were of two different crystal structures, and furthermore 2 and $4 \%$ concentrations of $10-\mathrm{nm}$ particles were not available from the vendor to conclusively evaluate the effect of volumetric concentration on $\mathrm{pH}$ for this nanofluid.

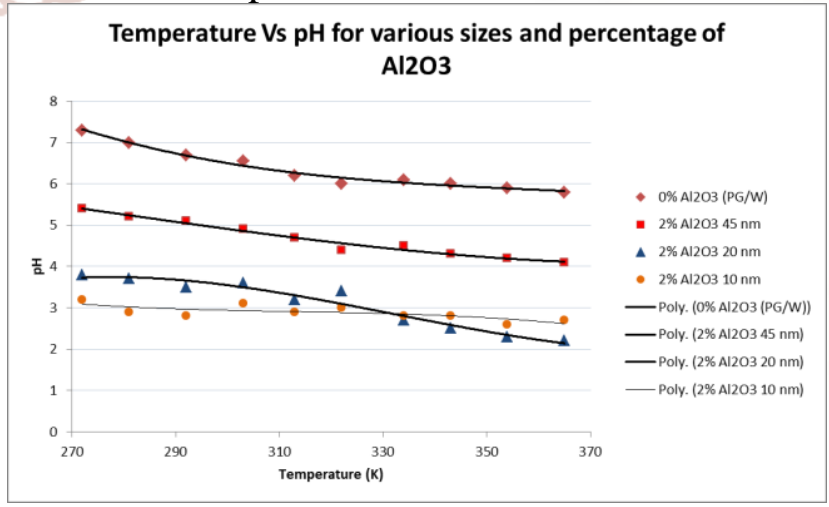

Figure 5: Comparison between the $\mathrm{pH}$ of the $\mathrm{Al} 2 \mathrm{O} 3$ nanofluid as a function of temperature containing 10-, 20-, and 45-nm particles. 


\section{Silicon Dioxide Nanofluid}

Figure 6 shows the variation in $\mathrm{pH}$ of the $\mathrm{SiO} 2$ nanofluid with temperature. Only one average particle size of $30 \mathrm{~nm}$ for this nanofluid was available from the manufacturer. Similar to the observation for $\mathrm{A} 2 \mathrm{O} 3$ nanofluids, the $\mathrm{pH}$ of $\mathrm{SiO} 2$ nanofluid also decreases with an increase in temperature following a second order polynomial trend for a constant concentration, in the temperature range of $273 \mathrm{~K}$ to $363 \mathrm{~K}$. As an example, the $\mathrm{pH}$ data of the $3 \% \mathrm{SiO} 2$ nanofluid match the expression

$$
\begin{gathered}
p H_{n f}=0.00001954 T^{2}-0.02469613 T+ \\
16.16886249 \text { with } R^{2}=0.9886
\end{gathered}
$$

Valid in the range $273 \mathrm{~K} \leq \mathrm{T} \leq 363 \mathrm{~K}$

Again, as observed in Figure 5 for the $\mathrm{Al} 2 \mathrm{O} 3$ nanofluids, the $\mathrm{pH}$ of $\mathrm{SiO} 2$ nanofluid also increases with an increase in the volumetric concentration of particles. The $\mathrm{pH}$ of the $5 \%$ volumetric concentration nanofluid is consistently higher than the $\mathrm{pH}$ of the $1 \%$ concentration throughout the temperature range. From the experimental data in Figure 6, it was observed that the addition of $\mathrm{SiO} 2$ nanoparticles imparted a substantial alkaline characteristic to the nanofluid.

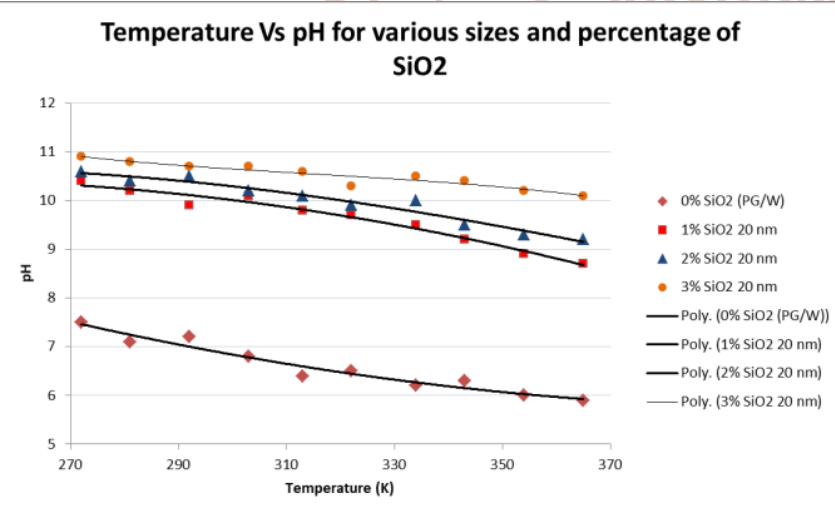

Figure 6: The variation of $\mathrm{pH}$ with temperature for the $\mathrm{SiO} 2$ nanofluid in $\mathrm{PG} / \mathrm{W}$

(60:40) base fluid for particle concentration ranging from 0 to $3 \%$.

\section{Zinc Oxide Nanofluid}

Figure 7 shows a comparison of the $\mathrm{pH}$ between two zinc oxide nanofluids containing 36 and $70 \mathrm{~nm}$ average particle sizes. Similar to the observations made for $\mathrm{Al} 2 \mathrm{O} 3$ and $\mathrm{SiO} 2$ nanofluids, the $\mathrm{pH}$ of $\mathrm{ZnO}$ nanofluid decreases with an increase in temperature. The $\mathrm{pH}$ variation with temperature fits a second-order polynomial. As an example, for $1 \% \mathrm{ZnO}$ nanofluid of $70 \mathrm{~nm}$ particle size, the $\mathrm{pH}$ can be expressed as

$$
\begin{gathered}
p H_{n f}=0.00018460 T^{2}-0.13511495 T+ \\
30.57413364 \text { with } R^{2}=0.9510
\end{gathered}
$$

Valid in the range $273 \mathrm{~K} \leq \mathrm{T} \leq 363 \mathrm{~K}$. Zinc oxide nanofluid also confirms similar trends exhibited by $\mathrm{Al} 2 \mathrm{O} 3$ and $\mathrm{SiO} 2$ nanofluids; (i) For the same temperature and concentration, the $\mathrm{pH}$ is higher for larger diameter (70-nm) particles. (ii) For the same temperature, as concentration increases the $\mathrm{pH}$ also increases. This trend is more pronounced for larger particles $(70 \mathrm{~nm})$ compared to the smaller particles $(36 \mathrm{~nm})$. From Figure 7 we observe that the $\mathrm{pH}$ of the base fluid lies in between the $\mathrm{pH}$ of the two nanofluids having two different particle sizes (36 and $70 \mathrm{~nm}$ ). It is further noticed that the $36-\mathrm{nm}$ nanofluid exhibits more acidic characteristic than the $70-\mathrm{nm}$ nanofluid.

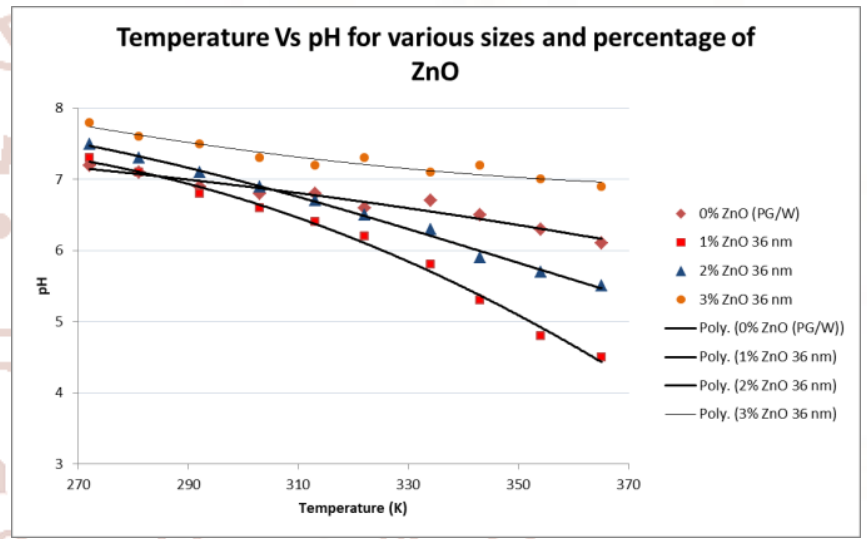

Figure 7: Comparison between the $\mathrm{pH}$ of $\mathrm{ZnO}$ nanofluid as a function of temperature of particle size $36 \mathrm{~nm}$.

\section{DEVELOPMENT OF CORRELATION Guidance from Experimental Data}

From the experimental results analysed from Figures 5 through 8 , it was established that the $\mathrm{pH}$ levels of nanofluids were dependent on the fluid temperature, nanoparticle volumetric concentration, and nanoparticle diameter. To establish the influence of each of these parameters on the $\mathrm{pH}$, the following analyses were conducted by varying each of those parameters independently. To make the correlation independent of units, the $\mathrm{pH}$ of nanofluid $\left(p \mathrm{H}_{n f}\right)$ was nondimensionalized by that of the base fluid $\left(p H_{b f}\right)$ using Eq. (2).

\section{Influence of Temperature}

The $\mathrm{pH}$ levels of each nanofluid $\left(\mathrm{pH}_{n f}\right)$ in Figures 5, 6 , and 7 were non-dimensionalized with the base fluid $\left(p H_{b f}\right)$ and were plotted against the nondimensionalized temperature $\left(\frac{T}{T_{0}}\right)$, for fixed concentration and fixed particle sizes. It was observed that the $\mathrm{pH}$ ratio $\left(\frac{p H_{n f}}{p H_{b f}}\right)$ followed a second-order 
polynomial in $\left(\frac{T}{T_{0}}\right)$. A careful analysis of base fluid data in Eq. (2) had confirmed thatthe variation of $\left(p H_{n f}\right)$ was a second-order polynomial innondimensional temperature $\left(\frac{T}{T_{0}}\right)$. The same trend was observed fromthe data of all three nanofluids. Therefore, the best-fit correlation for $\left(\frac{p H_{n f}}{p H_{b f}}\right)$ emerged as a function of $\left(\frac{T}{T_{0}}\right)$ in the followingform:

$$
\frac{p H_{n f}}{p H_{b f}}=a_{1}\left(\frac{T}{T_{0}}\right)^{2}+a_{2}\left(\frac{T}{T_{0}}\right)+a_{3}
$$

\section{Influence of Average Particle Size}

Figures 5, 6, and 7 revealed that the $\mathrm{pH}$ values increased as the particle sizes increased for fixed temperature and concentration. Therefore, to evaluate this functional nature of the variation of the $\mathrm{pH}$ ratio with the particle size, the experimental values of $\left(\frac{p H_{n f}}{p H_{b f}}\right)$ of each nanofluid were plotted against its nondimensional average particle sizes $\left(\frac{d}{d_{0}}\right)$. The particle size $\mathrm{d}$ varied from 10 to $70 \mathrm{~nm}$ and $\mathrm{d} 0$, and the reference average particle size was adopted to be 100 $\mathrm{nm}$. It is generally accepted in the nanofluids research literature that $100 \mathrm{~nm}$ is the upper limit for nanoparticles to ensure a stable suspension. Larger particlesizes will lead to settling of particles, nullifying the advantage of a nanofluid as a successful heat transfer fluid. Therefore, a $d_{0}$ value of $100 \mathrm{~nm}$ is appropriate. However, $d_{0}$ is simply areference value to obtain a non-dimensional correlation as Eq. (8). Therefore, any realistic diameter within the size range of 10 to $100 \mathrm{~nm}$ will serve the purpose. From these plots it wasdetermined that the variation of the $\mathrm{pH}$ with an average particle size for each nanofluid followed a second-order relation,

$$
\frac{\mathrm{pH}_{\mathrm{nf}}}{\mathrm{pH_{ \textrm {nb } }}}=\mathrm{c}_{1}\left(\frac{\mathrm{d}}{\mathrm{d}_{0}}\right)^{2}+\mathrm{c}_{2}
$$

This agrees with the fact that the $\mathrm{pH}$ depends on the surface charge of the particles and thus is a surface phenomenon. Therefore, $\mathrm{pH}$ may be proportional to the surface area $\left(d^{2}\right)$.

\section{Combined Correlation}

From these individual analyses of the influence of each parameter, it was concluded that a correlation in the following format would be appropriate for the $\mathrm{pH}$ of nanofluids:

$$
\frac{p H_{n f}}{p H_{b f}}=\left[a_{1}\left(\frac{T}{T_{0}}\right)^{2}+a_{2}\left(\frac{T}{T_{0}}\right)+a_{3}\right]\left[c_{1}\left(\frac{d}{d_{0}}\right)^{2}+c_{2}\right] \text { (9) }
$$

Next the statistical package LAB fit [20] was used to determine the unknown regression coefficients of Eq. (9) for different nanofluids from their experimental data. The regression coefficients from the statistical analysis are tabulated in Table 2. Equation (9) with coefficients of Table 2 has a range of validity $273 \mathrm{~K} \leq$ $\mathrm{T} \leq 363 \mathrm{~K} ; 1 \% \leq \varphi \leq 5 \%$; and $10 \mathrm{~nm} \leq \mathrm{d} \leq 70 \mathrm{~nm}$.

Table 2: Regression coefficients of the $\mathrm{pH}$ correlation (Eq. (10)) for different nanofluids

\begin{tabular}{|l|l|l|l|}
\hline & $\mathrm{Al2O3}$ & $\mathrm{SiO} 2$ & $\mathrm{ZnO}$ \\
\hline a1 & -0.1714584 & -0.1404768 & -0.1404768 \\
\hline a2 & 0.376192 & 0.1858231 & 0.1858231 \\
\hline a3 & -0.13514079 & -0.13514079 & 0.40701076 \\
\hline c1 & 33.8946855 & 0.746912628 & 0.44459085 \\
\hline c2 & 12.0607088 & 2.296413168 & 1.3669126 \\
\hline R2 & 0.98 & 0.97 & 0.98 \\
\hline Maximum deviation, \% & $-10 \%$ & $+12 \%$ & $+8 \%$ \\
\hline Average deviation, \% & $1.50 \%$ & $3.37 \%$ & $1.56 \%$ \\
\hline
\end{tabular}

\section{Comparison of Experimental Values with Correlation}

Comparison of the $\mathrm{pH}$ values predicted by the correlation (Eq. (9)) and the experimental values for the Al2O3 nanofluid is shown as an example in Figure 8 using the software mat lab[21]. The central line represents a perfect match between the experimental and correlation values and the two dashed lines are the $95 \%$ prediction bounds. Only 2 data points out of about 130 data points fall outside the $95 \%$ prediction bounds on the lower side. Given a specific concentration, diameter, and temperature of this nanofluid within the curve-fit range, the correlation ensures $95 \%$ confidence that the value will be between the lower and upper prediction limits. 


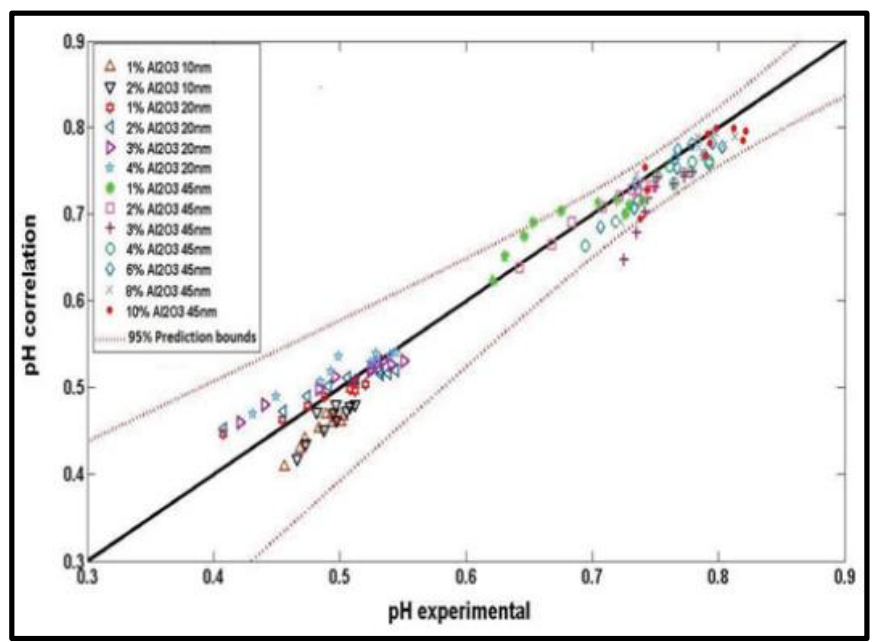

Figure 8: Comparison of the $\mathrm{pH}$ of $\mathrm{Al} 2 \mathrm{O} 3$ nanofluid values calculated fromthe present correlation, Eq. (9), with the values obtained from the experiments.

\section{CONCLUSIONS}

The $\mathrm{pH}$ values of three nanofluids were measured and found to be functions of temperature, volumetric concentration, and particle diameter. The $-\mathrm{pH}$ exhibited a strong dependence on temperature. For the $\mathrm{A} 12 \mathrm{O} 3$ nanofluid an increase of about $35 \%$ in $\mathrm{pH}$ was observed for a temperature rise of about $30 \%$. For the same nanofluid with larger particle sizes, an increase of about 4 to $21 \%$ in $\mathrm{pH}$ was observed for a particle volumetric concentration increase from 1 to $4 \%$. The $\mathrm{pH}$ was found to be proportional to the square of particle diameter. We observed that the nanoparticles addition to the base fluid PG/W (60:40), which was essentially acidic, turned it alkaline in nature with $\mathrm{SiO} 2$ particles. For $\mathrm{A} 12 \mathrm{O} 3$ as well as $\mathrm{ZnO}$ nanofluids, larger particles made the nanofluid less acidic. From experimental data a correlation was developed (Eq. (10)) that is suitable for the prediction of the $\mathrm{pH}$ of these nanofluids. It is acknowledged that due to the difference in dispersant and crystal structure of particles of nanofluids, the correlation presented herein may not be universal. However, this may be a first step in proposing a correlation for estimating the $\mathrm{pH}$ of nanofluids. With future research this correlation can be improved to be valid for other nanofluids, such as copper oxide, titanium dioxide, and carbon nanotube suspensions.

\section{REFERENCES}

1. Nalwa, H. S., Handbook of Nanostructured Materials and Nanotechnology, Vol. 2, Academic Press, San Diego, CA, 2000.

2. Li, X. F., Zhu, D. S., Wang, X. J., Wang, N., Gao, J. W., and Li, H., Thermal Conductivity Enhancement Dependent $\mathrm{pH}$ and Chemical
Surfactant for $\mathrm{Cu}-\mathrm{H} 2 \mathrm{O}$ Nanofluids, ThermochimicaActa, vol. 469, no. 1-2, pp. 98103, 2008.

3. Li, X. F., Zhu, D. S., and Wang, X., Evaluation on Dispersion Behavior of the Aqueous Copper Nano-Suspensions, Journal of Colloid and Interface Science, vol. 310, no. 2, pp. 456-463, 2007.

4. Wang, X. J., Zhu, D. S., and Yang, S., Investigation of $\mathrm{pH}$ and SDBS on Enhancement of Thermal Conductivity in Nanofluid, Chemical Physics Letters, vol. 470, no. 1-3, pp. 107-111, 2009.

5. Zhu, D. S., Li, X. F., Wang, N., Wang, X. J., Gao, J. W., and Li, H., Dispersion Behavior and Thermal Conductivity Characteristics of Al2O3H2O Nanofluids, Current Applied Physics, vol. 9, no. 1, pp. 131-139, 2009.

6. Lee, D., Kim, J. W., and Kim, B. G., A New Parameter to Control Heat Transport in Nanofluids: Surface Charge State of the Particle in Suspension, Journal of Physical Chemistry B, vol. 110, no. 9, pp. 4323-4328, 2006.

7. Wamkam, C. T., Opoku, M. K., Hong, H., and Smith, P., Effects of $\mathrm{pH}$ on Heat Transfer Nanofluids Containing $\mathrm{ZrO} 2$ and $\mathrm{TiO} 2$ Nanoparticles, Journal of Applied Physics, vol. 109, no. 2, pp. 024305-1 to 024305-5, 2011.

8. Younes, H., Christensen, G., Luan, X., Hong, H., and Smith, P., Effects of Alignment, $\mathrm{pH}$, Surfactant, and Solvent on Heat Transfer Nanofluids Containing $\mathrm{Fe} 2 \mathrm{O} 3$ and $\mathrm{CuO}$ Nanoparticles, Journal of Applied Physics, vol. 111, no. 6, pp. 064308-1 to 064308-7, 2012.

9. Huang, J., Wang, X., Long, Q., Wen, X., Zhou, Y., and Li, L.,'Influence of $\mathrm{pH}$ on the Stability Characteristics of Nanofluids, Proc. IEEE: The International Symposium on Photonics and Optoelectronics (SOPO), Wuhan, China, pp.1-4, 2009.

10. Timofeeva, E. V., Routbort, J. L., and Singh, D., Shape Effects on Thermophysical Properties of Alumina Nanofluids, Journal of Applied Physics, vol. 106, no. 1, pp.014304-1 to 014304-10, 2009.

11. Kulkarni, D. P., Namburu, P. K., Bargar, H. E., and Das, D. K., Convective Heat Transfer and Fluid Dynamic Characteristics of SiO2-Ethylene Glycol/Water Nanofluid, Heat 
Transfer Engineering, vol. 29, no. 12, pp. 10271035,2008 .

12. Aesar, Alfa, http://www.alfaaesar.com, accessed 2007.

13. Nanostructured and Amorphous Materials, Inc., http://www.nanoamor.com, accessed 2010.

14. Bransonictabletop ultrasonic cleaners, Branson Ultrasonic Corporation, Danbury, CT, 2010.

15. Experimental Operating and Maintenance Procedures for $\mathrm{pH}$ of Liquids Unit, Hanna Instruments, Woonsocket, RI, 2009.

16. VWR Model 320 Heater, http://www.vwr.com, accessed 2009.
17. Nordstorm, D. K., Alpers, C. N., Ptacek, C. J., and Blowes, D. W., Negative $\mathrm{pH}$ and Extremely Acidic Mine Waters From Iron Mountain, California, Environmental Science \& Technology, vol. 34, no. 2, pp. 254-258, 2000.

18. Lim, K. F., Negative pH Does Exist, Journal of Chemical Education, vol. 83, no. 10, pp. 1465, 2006.

19. Environmental Test Chamber Model FS 202 chamber 144, Associated Environmental Systems, Lawrence, MA, 2002.

20. Silva, W. P., and Silva, C. M. D. P. S., LAB Fit Curve Fitting Software (Nonlinear Regression and Treatment of Data Program) V 7.2.42 (19992008), online, www.labfit.net,accessed 2008. 